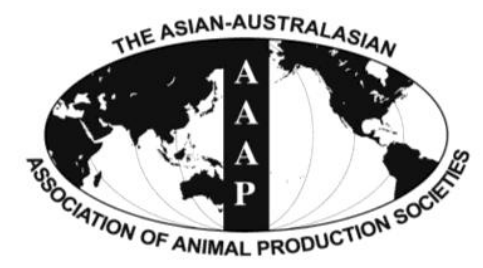

Asian-Aust. J. Anim. Sci.

Vol. 25, No. 12 : 1726-1733 December 2012

http://dx.doi.org/10.5713/ajas.2012.12305

www.ajas.info

pISSN 1011-2367 elSSN 1976-5517

\title{
Effect of Fibre Level and Fibre Source on Gut Morphology and Micro-environment in Local (Mong Cai) and Exotic (LandracexYorkshire) Pigs
}

\author{
T. T. B. Ngoc, T. T. T. Hong ${ }^{1}$, N. T. Len ${ }^{2}$ and J. E. Lindberg ${ }^{3} *$ \\ Department of Animal Nutrition and Forage, National Institute of Animal Sciences, Hanoi, Vietnam
}

\begin{abstract}
The effect of genotype, fibre level and fibre source on gut morphology, environment and microflora was studied using 18 Mong Cai (MC) and 18 LandracexYorkshire (LY) pigs, aged around $60 \mathrm{~d}$. The diets were based on maize, rice bran, soybean meal, fish meal and soybean oil, and cassava residue (CR) or brewer's grain (BG) as fibrous ingredient sources in the high-fibre diets (HF). A low-fibre diet (LF), containing around $200 \mathrm{~g} \mathrm{NDF} / \mathrm{kg}$ dry matter (DM), was formulated without CR and BG as feed ingredients. The HF diets (HF-CR and HF-BG) were formulated to contain around $270 \mathrm{~g}$ NDF $/ \mathrm{kg}$ DM. The experiment was arranged according to a $2 \times 3$ factorial completely randomized design with six replications, and lasted $30 \mathrm{~d}$. Crypt density in ileum was lowest $(\mathrm{p}<0.05)$ and villus height in jejunum and ileum were the greatest $(\mathrm{p}<0.05)$ in pigs fed diet HF-BG. Villus width in ileum was greatest in pigs fed diets HF$\mathrm{CR}$ and HF-BG $(\mathrm{p}<0.05)$. Lactic acid bacteria $(\mathrm{LAB})$ counts in stomach were greatest $(\mathrm{p}<0.05)$ and $E$. coli counts in ileum and colon were lowest $(\mathrm{p}<0.05)$ in pigs fed diet HF-CR. The concentration of total organic acids in ileum, caecum and colon were greatest $(\mathrm{p}<0.05)$, and $\mathrm{pH}$ in ileum and colon were lowest $(\mathrm{p}<0.05)$ in pigs fed diet HF-CR. Crypt density in ileum was lowest, and villus height in ileum and villus width in jejunum and ileum was greatest in LY pigs $(\mathrm{p}<0.05)$. LAB counts in stomach and ileum were greatest, and $E$. coli counts in ileum were lowest in MC pigs $(\mathrm{p}<0.05)$. The concentration of total organic acids in ileum, caecum and colon were greatest $(\mathrm{p}<0.05)$ and $\mathrm{pH}$ lowest $(\mathrm{p}<0.05)$ in MC pigs. (Key Words: Genotype, Dietary Fibre, Lactic Acid Bacteria, Organic Acids, Villi)
\end{abstract}

\section{INTRODUCTION}

The maintenance of gut health is complex and relies on a delicate balance between the diet, the commensal microflora and the mucosa, including the digestive epithelium and the mucus overlying the epithelium (Montage et al., 2003). The diet has an important influence on gut health, and it can provide either beneficial or harmful input. Dietary fibre (DF) is a feed component that has major influence in this regard. Dietary fibre components are not digested by endogenous digestive enzymes, and consequently are the main substrates for bacterial

\footnotetext{
* Corresponding Author: J. E. Lindberg. Tel: +46-(0)18-672102, Fax: +46-(0)18-672995, E-mail: Jan.Erik.Lindberg@ slu.se

${ }^{1}$ Hue University of Agriculture and Forestry, Hue, Vietnam.

${ }^{2}$ Department of Livestock Production, Ministry of Agriculture and Rural Development, Hanoi, Vietnam.

3 Department of Animal Nutrition and Management, Swedish University of Agricultural Sciences, P.O. Box 7024, 75007 Uppsala, Sweden.

Submitted May 31, 2012; Accepted Jul. 3, 2012; Revised Jul. 11, 2012
}

fermentation in the distal part of the gut. The main products of fermentation are short chain organic acids (OA), predominantly lactate, acetate, propionate and butyrate. The OA have been suggested to develop the growth of the digestive tract, by stimulating epithelium cell proliferation (Montage et al., 2003). In an acidic environment, OA can inhibit the growth of enteric bacterial pathogens, such as Salmonella, Escherichia coli and Clostridium species (Hentges, 1992; Wang and Gibson, 1993; May et al., 1994). Studies in pigs have shown that the various types of plant carbohydrates behave differently in the gastrointestinal tract (GIT) depending on their structural characteristics. Inclusion of soluble non-starch polysaccharides (NSP) in the diet can stimulate the growth of commensal gut microbes, leading to increased production of $\mathrm{OA}$, and a lower $\mathrm{pH}$ in the large intestine (Bach Knudsen et al., 1991). Insoluble NSP reduce the transit time and provide substrate that is slowly degradable by the microbiota in the distal large intestine (Freire et al., 2000), and modulate gut morphology by increasing villus length (Hedemann et al., 2006). 
The aim of the current study was to examine the impact of fibre level and fibre source in the diet on gut morphology, environment and selected bacteria at different sites of the digestive tract of local (Mong Cai, MC) and exotic (Landrace $\times$ Yorkshire, LY) pigs.

\section{MATERIALS AND METHODS}

\section{Location}

The experiment was carried out at the Centre of Animal Feed Testing and Conservation, National Institute of Animal Sciences (NIAS), Hanoi, Vietnam. The experiment was approved by the Animal Science Committee of NIAS.

\section{Experimental feeds}

The diets were based on maize, rice bran, soybean meal, fish meal and soybean oil, and cassava residue (CR) or brewer's grain $(\mathrm{BG})$ as fibrous ingredient sources in the high-fibre diets (HF). A low-fibre diet (LF), containing around $200 \mathrm{~g} \mathrm{NDF} / \mathrm{kg}$ dry matter (DM), was formulated without $\mathrm{CR}$ and $\mathrm{BG}$ as feed ingredients. The HF diets (HF$\mathrm{CR}$ and HF-BG) were formulated to contain around $270 \mathrm{~g}$ $\mathrm{NDF} / \mathrm{kg}$ DM. All diets were formulated to contain equal concentrations of metabolizable energy (ME), crude protein (CP), essential amino acids, minerals and vitamins to meet requirements for growing/finishing pigs according to NRC (1998) (Tables 1 and 2).

Feed ingredients were stored in plastic bags to avoid moisture entering before mixing the diets. The diets were mixed every $7 \mathrm{~d}$ and put into plastic bags in order to maintain the quality of the feed. The diet was offered in mash form.

\section{Experimental design}

A total of 36 pigs (18 MC and $18 \mathrm{LY}$ ), aged around 60

Table 1. Ingredient composition ( $\mathrm{g} / \mathrm{kg}$, air-dry basis) of the experimental diets

\begin{tabular}{lccc}
\hline & \multicolumn{3}{c}{ Diet $^{\mathrm{a}}$} \\
\cline { 2 - 4 } & LF & HF-CR & HF-BG \\
\hline Maize & 516.5 & 116.5 & 365 \\
Soybean meal & 230 & 270 & 92.5 \\
Fish meal & 50 & 60 & 20 \\
Rice bran & 170 & 150 & 150 \\
Cassava residue & 0 & 350 & 0 \\
Brewer's grain & 0 & 0 & 300 \\
Soybean oil & 0 & 20 & 40 \\
Dicalcium phosphate & 10 & 10 & 10 \\
Limestone & 15 & 15 & 15 \\
Mineral-vitamin premix & 2.5 & 2.5 & 2.5 \\
Methionine & 3 & 3 & 2 \\
Salt (NaCl) & 3 & 3 & 3 \\
\hline a LF $=$ Low fibr
\end{tabular}

${ }^{a}$ LF = Low fibre diet; HF-CR = High fibre diet containing cassava residue; $\mathrm{HF}-\mathrm{BG}=$ High fibre diet containing brewer's grain.
Table 2. Analysed chemical composition ( $\mathrm{g} / \mathrm{kg}$, air-dry basis) of the experimental diets

\begin{tabular}{lccc}
\hline & \multicolumn{3}{c}{ Diet $^{\mathrm{a}}$} \\
\cline { 2 - 4 } & LF & HF-CR & HF-BG \\
\hline Dry matter & 893 & 906 & 916 \\
Crude protein & 187 & 181 & 185 \\
Lysine & 10.8 & 10.9 & 11.1 \\
Methionine+cystine & 8.8 & 8.1 & 8.5 \\
Threonine & 7.3 & 7.1 & 7.5 \\
Tryptophan & 2.5 & 2.3 & 2.9 \\
NDF & 198 & 265 & 276 \\
Cellulose & 66 & 89 & 96 \\
Total NSP & 183 & 221 & 242 \\
Insoluble NSP & 143 & 174 & 213 \\
Soluble NSP & 40 & 47 & 29 \\
Klason lignin & 44 & 39 & 62 \\
DF & 227 & 260 & 304 \\
Starch & 318 & 290 & 240 \\
GE (MJ/kg, air-dry basis) & 15.5 & 15.7 & 16.1 \\
ME (MJ/kg, air-dry basis) & 12.3 & 11.7 & 11.5 \\
\hline
\end{tabular}

NSP = Non-starch polysaccharides; DF = Dietary fibre; GE = Gross energy; $\mathrm{ME}=$ Metabolisable energy.

${ }^{a}$ LF = Low fibre diet; HF-CR = High fibre diet containing cassava residue; HF-BG = High fibre diet containing brewer's grain

${ }^{\mathrm{b}}$ Calculated based on Composition and Nutritive Value of Animal Feeds in Vietnam (NIAH, 2001).

days, were used in this experiment. The MC pigs were bought from the Mong Cai Farm in Quang Ninh province and the LY pigs from the Pig Research Centre in Hanoi. The initial body weight of the MC pigs was $9.5 \pm 0.4 \mathrm{~kg}$ and of the LY pigs $16.5 \pm 0.4 \mathrm{~kg}$. Before the experiment started, all animals were vaccinated against Hog cholera, pasteurellosis, pneumonia and paratyphoid. The pigs were kept individually in concrete floored pens $(1.8 \mathrm{~m} \times 0.8 \mathrm{~m})$, fully covered with wooden slats, in an open-sided house. The pens and the troughs were cleaned every day. The animals had free access to feed and water.

The experiment was structured according to a completely randomized $2 \times 3$ factorial design, with two breeds (MC and LY) and three diets (LF, HF-CR and HF$\mathrm{BG}$ ). The animals were selected from six litters (3 litters for MC and 3 litters for LY) with an equal number of males and females and were distributed equally among the treatments. Each treatment consisted of 6 pens, with one pig per pen as a replicate. The length of the experiment was $27 \mathrm{~d}$.

\section{Collection of digesta samples}

At the end of experiment, after a 4-h fasting period in the morning, the pigs were injected with Thiopental (20 $\mathrm{mg} / \mathrm{kg} \mathrm{BW}$ ), and then slaughtered and immediately eviscerated. The different sampling sites were identified and tied off.

Digesta samples were collected from the stomach, ileum 
(about $100 \mathrm{~cm}$ of small intestine before the ileo-caecal ostium), caecum and colon (about $50 \mathrm{~cm}$ beyond the caecalcolon junction). The digesta collected from all sampling sites was immediately transferred to plastic jars in a cooling container with ice, $\mathrm{pH}$ was recorded with a $\mathrm{pH}$-meter (Hanna HI 8424, Italia) and samples were taken for bacterial enumeration and for analysis of OA. The samples for organic acid analysis were then frozen at $-20^{\circ} \mathrm{C}$ and kept frozen until analysis.

\section{Bacterial enumerations}

The bacterial flora in digesta samples were estimated immediately after collection by culture methods using selective media. Digesta samples were diluted with sterile $0.9 \% \mathrm{NaCl}$ solution in a 1:10 dilution. Secondary dilutions were from $10^{-2}$ to $10^{-4}$ for samples taken from the stomach and from $10^{-2}$ to $10^{-9}$ for the digesta taken from the other segments to estimate the E. coli population. For estimation of the lactic acid bacteria (LAB) population, the dilutions were from $10^{-6}$ to $10^{-9}$ for samples taken from the stomach and ileum and from $10^{-7}$ to $10^{-9}$ for samples taken from the colon. For enumeration of the total number of E. coli, the suspensions were spread on EMB (Eosin Methylene Blue) agar (Difco) and incubated under aerobic conditions at $37^{\circ} \mathrm{C}$ for $24 \mathrm{~h}$. Colonies with green metallic sheen were counted as E. coli. For total number of LAB, the suspensions were spread on MRS (de Man, Rogosa and Sharp) agar (Merck), and incubated at $37^{\circ} \mathrm{C}$ for $48 \mathrm{~h}$ under anaerobic conditions. Each dilution was performed in duplicate and result was the average of 2 dilutions. The digesta microbial enumerations are expressed as $\log _{10}$ colony forming units (CFU) in fresh matter.

\section{Tissue sampling}

The digestive tract was removed and sections of the duodenum (approximately $10 \mathrm{~cm}$ from stomach sphincter), the jejunum (5.5 $\mathrm{m}$ from stomach sphincter) and the ileum (10 $\mathrm{cm}$ prior to the ileo-caecal orifice) were excised and opened along their length at the mesenteric border and fixed in $10 \%$ formaldehyde solution and embedded in paraffin wax. These tissue samples were cut in transverse section in $5 \mu \mathrm{m}$ thick slices and were stained with haematoxylin and eosin. Villus height and width, and density of crypts were measured at 50×magnification using a Zeiss Axioplan 2 microscope and image-analyzing software KS 4002.0 (Koltrol Eletronic, Munique, Germany). A total of 3 slides were cut from each tissue sample and villus height and width were evaluated on 10 well-oriented villi on each slide from ileum samples. Measurements were only made where the villus-crypt unit was perpendicular to the muscularis mucosa. Villus height was the distance from the top of the villus to the villus-crypt junction, and villus width was the distance between one side of the brush border membrane to the other side of the brush border membrane. The density of crypts was determined as the number of crypts present over a defined distance across the luminal part of mucosa.

\section{Chemical analysis}

All feed samples were dried at $60^{\circ} \mathrm{C}$ and ground through a $1 \mathrm{~mm}$ sieve before analysis. Dry matter (967.03), CP (984.13) and ash (942.05) were analysed according to the AOAC methods (AOAC, 1990), and CP content was calculated as nitrogen $\times 6.25$. The NDF was determined by the method of Van Soest et al. (1991). Amino acids were determined by high-performance chromatography using an ion exchange column (Amino Quant, 1990). Starch was analysed by an enzymatic method (Larsson and Bengtsson, 1983). Gross energy (GE) was determined with a bomb calorimeter (Model: C2000 Basic - IKA Co., Germany).

Total, soluble and insoluble NSP and their constituent sugars were determined as alditol acetates by gas-liquid chromatography for neutral sugars, and by a colorimetric method for uronic acids using a modification of the Uppsala method (Theander et al., 1995) as described by Bach Knudsen (1997). Klason lignin was determined as the $12 \mathrm{M}$ $\mathrm{H}_{2} \mathrm{SO}_{4}$ insoluble residue. Total DF is the sum of Klason lignin and total NSP.

Content of different fibre fractions were calculated as follows:

$$
\begin{aligned}
& \text { Cellulose = NSP glucose }\left(12 \mathrm{~mol} / \mathrm{L} \mathrm{H}_{2} \mathrm{SO}_{4}\right) \\
& \text {-NSP glucose }\left(2 \mathrm{~mol} / \mathrm{L} \mathrm{H}_{2} \mathrm{SO}_{4}\right)
\end{aligned}
$$

\section{Total NSP $=$ Total NCP+cellulose}

$$
\text { Soluble NCP }=\text { Total NCP-insoluble NCP }
$$

Concentration of individual OA in digesta samples from different gut segments were determined by highperformance liquid chromatography (Shimadzu, Japan) (Food Components Adhoc Committee, 2002).

\section{Statistical analysis}

The data were analysed as a $2 \times 3$ factorial completely randomized design with diet, breed and interaction (diet by breed) as factors using the GLM procedure of Minitab Software, version 13.31 (Minitab, 2000). Treatment means which showed significant differences at the probability level of $\mathrm{p}<0.05$ were compared using Tukey's pairwise comparison procedure.

The statistical model used was as follows: 
Table 3. Effect of dietary fibre source on intestinal morphology of Mong Cai (MC) and Landrace $\times$ Yorkshire (LY) pigs

\begin{tabular}{|c|c|c|c|c|c|c|c|c|c|}
\hline & \multicolumn{2}{|c|}{ Breed (B) } & \multicolumn{3}{|c|}{$\operatorname{Diet}(\mathrm{D})^{\mathrm{a}}$} & \multirow{2}{*}{ SEM } & \multicolumn{3}{|c|}{ p-value } \\
\hline & LY & $\mathrm{MC}$ & $\mathrm{LF}$ & HF-CR & HF-BG & & $\mathrm{B}$ & $\mathrm{D}$ & $\mathrm{B} \times \mathrm{D}$ \\
\hline \multicolumn{10}{|c|}{ Crypt density (no/mm²) } \\
\hline Duodenum & 20.6 & 22.2 & 22.9 & 21.6 & 19.7 & 1.1 & NS & NS & NS \\
\hline Jejunum & 19.8 & 22.4 & 21.7 & 21.8 & 19.8 & 1.5 & NS & NS & NS \\
\hline Ileum & 16.0 & 18.8 & $19.4^{\mathrm{a}}$ & $16.8^{\mathrm{ab}}$ & $16.1^{\mathrm{b}}$ & 0.9 & $* *$ & $*$ & NS \\
\hline \multicolumn{10}{|c|}{ Villus height $(\mu \mathrm{m})$} \\
\hline Duodenum & 320 & 311 & 320 & 319 & 307 & 16 & NS & NS & NS \\
\hline Jejunum & 298 & 283 & $269^{\mathrm{a}}$ & $284^{\mathrm{a}}$ & $318^{\mathrm{b}}$ & 11 & NS & $* *$ & NS \\
\hline Ileum & 273 & 259 & $241^{\mathrm{a}}$ & $258^{\mathrm{a}}$ & $300^{\mathrm{b}}$ & 17 & $*$ & $* * *$ & NS \\
\hline \multicolumn{10}{|c|}{ Villus width $(\mu \mathrm{m})$} \\
\hline Duodenum & 164 & 175 & 165 & 166 & 178 & 15 & NS & NS & NS \\
\hline Jejunum & 162 & 136 & 145 & 153 & 149 & 7 & $* *$ & NS & NS \\
\hline Ileum & 175 & 165 & $152^{\mathrm{a}}$ & $174^{\mathrm{b}}$ & $183^{\mathrm{b}}$ & 10 & $*$ & $* * *$ & NS \\
\hline
\end{tabular}

$* \mathrm{p}<0.05 ; * * \mathrm{p}<0.01 ; * * * \mathrm{p}<0.001 ; \mathrm{NS}=$ Non-significant.

${ }^{\mathrm{a}} \mathrm{LF}=$ Low fibre diet; HF-CR = High fibre diet containing cassava residue; HF-BG = High fibre diet containing brewer's grain.

$Y_{i j}=\mu+D_{i}+B_{j}+\left(D_{i} \times B_{j}\right)+e_{i j}$

Where: $\mathrm{Y}_{\mathrm{ij}}=$ bacteria counts or concentration of lactic acid or volatile fatty acids (VFA), $\mu=$ overall mean, $D_{i}=$ effect of diet $i, B_{j}=$ effect of breed $j,\left(D_{i} \times B_{j}\right)=$ interaction between diet $\mathrm{i}$ and breed $\mathrm{j}$, and $\mathrm{e}_{\mathrm{ij}}=$ random error.

\section{RESULTS}

\section{Gut morphology}

The intestinal morphology in different intestinal segments is shown in Table 3. There were no differences in the crypt density, and villus height in the duodenum and jejunum between MC and LY pigs ( $\mathrm{p}>0.05$ ). In the ileum, the crypt density was higher in MC pigs than in LY pigs $(p<0.001)$, while the height of villi was shorter for MC pigs than for LY pigs. The villus width in the duodenum was not different between MC and LY pigs ( $p>0.05$ ), whereas LY pigs had greater villus width in the jejunum and ileum than MC pigs $(\mathrm{p}<0.05)$
The crypt density and villus width in the duodenum and jejunum were not affected by diet $(p>0.05)$. In the ileum, increased fibre level (diets HF-CR and HF-BG) resulted in decreased crypt density and increased villus width. The lowest crypt density in the ileum was found for diet HF-BG, while the lowest villus width in the ileum was found for diet LF. The height of villi in the jejunum and ileum was lower in diets HF-CR and LF than in diet HF-BG $(\mathrm{p}<0.01)$. There were no interactions for crypt density and villus height and width in all intestinal segments between breed and diet $(\mathrm{p}>0.05)$.

\section{Bacterial counts}

The breed had no effect $(\mathrm{p}>0.05)$ on the LAB and $E$. coli counts in the colon (Table 4$)$. There were differences $(\mathrm{p}<0.01)$ in the LAB counts in the stomach and ileum between MC and LY pigs, with higher values for MC pigs. The E. coli population in the stomach was lower for LY pigs than for MC pigs, while LY pigs has higher E. coli counts in the ileum compared with MC pigs.

Table 4. Effect of dietary fibre source on lactic acid bacteria (LAB) and E. coli counts ${ }^{\mathrm{a}}$ in different intestinal segments of Mong Cai (MC) and Landrace $\times$ Yorkshire (LY) pigs

\begin{tabular}{|c|c|c|c|c|c|c|c|c|c|}
\hline & \multicolumn{2}{|c|}{ Breed (B) } & \multicolumn{3}{|c|}{$\operatorname{Diet}(\mathrm{D})^{\mathrm{b}}$} & \multirow{2}{*}{ SEM } & \multicolumn{3}{|c|}{$\mathrm{p}$-value } \\
\hline & LY & $\mathrm{MC}$ & $\mathrm{LF}$ & HF-CR & HF-BG & & B & $\mathrm{D}$ & $\mathrm{B} \times \mathrm{D}$ \\
\hline \multicolumn{10}{|l|}{$\overline{\mathrm{LAB}}$} \\
\hline Stomach & 9.57 & 9.65 & $9.53^{\mathrm{a}}$ & $9.69^{\mathrm{b}}$ & $9.60^{\mathrm{c}}$ & 0.03 & $* *$ & $* * *$ & NS \\
\hline Ileum & 8.43 & 8.53 & $8.40^{\mathrm{a}}$ & $8.53^{\mathrm{b}}$ & $8.51^{\mathrm{b}}$ & 0.03 & $* * *$ & $* *$ & $* *$ \\
\hline Colon & 10.49 & 10.50 & 10.48 & 10.50 & 10.51 & 0.02 & NS & NS & NS \\
\hline \multicolumn{10}{|l|}{ E. coli } \\
\hline Stomach & 3.14 & 3.19 & 3.17 & 3.16 & 3.17 & 0.01 & $* *$ & NS & NS \\
\hline Ileum & 7.37 & 7.33 & $7.41^{\mathrm{a}}$ & $7.31^{\mathrm{b}}$ & $7.35^{\mathrm{c}}$ & 0.02 & $* *$ & $* *$ & NS \\
\hline Colon & 8.27 & 8.28 & $8.33^{\mathrm{a}}$ & $8.20^{\mathrm{b}}$ & $8.30^{\mathrm{a}}$ & 0.03 & NS & $* * *$ & NS \\
\hline
\end{tabular}

$* \mathrm{p}<0.05 ; * * \mathrm{p}<0.01 ; * * * \mathrm{p}<0.001 ; \mathrm{NS}=$ Non-significant.

${ }^{a}$ Bacterial number is expressed as $\log _{10} \mathrm{CFU} / \mathrm{g}$ fresh digesta.

${ }^{\mathrm{b}}$ LF, low fibre diet; HF-CR, high fibre diet containing cassava residue; HF-BG, high fibre diet containing brewer's grain. 
The LAB counts in the colon and E. coli counts in the stomach (Table 4$)$ were not affected by diet $(p>0.05)$. The LAB counts in the stomach was lowest in pigs fed diet LF $(p<0.001)$, followed by the pigs fed diet HF-BG and diet HF-CR, whereas the reverse pattern was true for the $E$. coli counts in the ileum $(p<0.01)$. The LAB population in the ileum was increased $(\mathrm{p}<0.01)$ by increased fibre level in the diet (diets HF-CR and HF-BG). The E. coli counts in the colon was similar in diets LF and HF-BG ( $>>0.05)$, while it was lower in diet HF-CR $(\mathrm{p}<0.001)$. There were no interactions in the counts of $\mathrm{LAB}$ and $E$. coli in all segments examined between breed and diet $(p>0.05)$, with exception of LAB counts in ileum $(p<0.05)$. Increased fibre level in the diet had an effect on LAB counts in MC pigs, but not in LY pigs.

\section{Gut environment}

There was a difference $(\mathrm{p}<0.01)$ in $\mathrm{pH}$ between $\mathrm{MC}$ and
LY pigs in all intestinal segments (Table 5), with lower values for MC pigs. The diet had effect on $\mathrm{pH}$ at all sites of the gut $(\mathrm{p}<0.05)$. The lowest $\mathrm{pH}$ value at all intestinal sites was found for diet HF-CR.

With the exception for the concentration of lactate in caecum and colon, and butyrate in ileum, MC pigs had higher (or a tendency to higher) concentration ( $p<0.05$ or $\mathrm{p}<0.1$ ) of total and individual OA (lactate, acetate, propionate, butyrate) and short chain fatty acids (SCFA) (Table 5) at all sampling sites in the GIT than LY pigs.

The concentration of total and individual OA were affected by diet $(\mathrm{p}<0.05)$, with exception of the concentration of lactate in the caecum $(p>0.05)$. The concentration of lactic acid in the ileum and colon was lowest for pigs fed diet LF, while it was highest for pigs fed diet HF-BG in ileum and for pigs fed diet HF-CR in colon $(p<0.05)$. However, at all intestinal sites the lowest acetate concentration was found for pigs fed diet LF and the

Table 5. Effect of dietary fibre source on $\mathrm{pH}$, concentrations of short chain fatty acids (SCFA-acetic, propionic and butyric acids) and organic acids (lactic acid and SCFA) (mmol/kg DM) in different intestinal segments of Mong Cai (MC) and Landrace $\times$ Yorkshire (LY) pigs

\begin{tabular}{|c|c|c|c|c|c|c|c|c|c|}
\hline & \multicolumn{2}{|c|}{ Breed (B) } & \multicolumn{3}{|c|}{ Diet (D)a } & \multirow{2}{*}{ SEM } & \multicolumn{3}{|c|}{ p-value } \\
\hline & LY & $\mathrm{MC}$ & $\mathrm{LF}$ & HF-CR & HF-BG & & $\mathrm{B}$ & $\mathrm{D}$ & $\mathrm{B} \times \mathrm{D}$ \\
\hline \multicolumn{10}{|l|}{$\overline{\mathrm{pH}}$} \\
\hline Ileum & 7.6 & 7.3 & $7.6^{\mathrm{a}}$ & $7.2^{\mathrm{b}}$ & $7.3^{\mathrm{b}}$ & 0.1 & $* *$ & $* *$ & NS \\
\hline Caecum & 6.6 & 5.8 & $6.2^{\mathrm{ab}}$ & $5.9^{\mathrm{a}}$ & $6.4^{\mathrm{b}}$ & 0.2 & $* * *$ & $*$ & NS \\
\hline Colon & 6.9 & 6.6 & $6.9 \mathrm{a}$ & $6.5^{\mathrm{b}}$ & $6.8^{\mathrm{a}}$ & 0.1 & $* *$ & $* *$ & NS \\
\hline \multicolumn{10}{|l|}{ Lactic acid } \\
\hline Ileum & 234 & 255 & $228^{a}$ & $248^{\mathrm{ab}}$ & $258^{\mathrm{b}}$ & 10 & $*$ & $*$ & NS \\
\hline Caecum & 49 & 51 & 45 & 53 & 52 & 4 & NS & NS & NS \\
\hline Colon & 139 & 150 & $108^{\mathrm{a}}$ & $171^{\mathrm{b}}$ & $155^{\mathrm{b}}$ & 11 & NS & $* * *$ & NS \\
\hline \multicolumn{10}{|l|}{ Acetic acid } \\
\hline Ileum & 129 & 140 & $100^{\mathrm{a}}$ & $179^{\mathrm{b}}$ & $125^{\mathrm{c}}$ & 8 & + & $* * *$ & NS \\
\hline Caecum & 433 & 470 & $419^{\mathrm{a}}$ & $478^{\mathrm{b}}$ & $456^{\mathrm{ab}}$ & 19 & $* *$ & $* *$ & NS \\
\hline Colon & 292 & 308 & $287^{\mathrm{a}}$ & $319^{\mathrm{b}}$ & $295^{\mathrm{ab}}$ & 13 & + & $* *$ & NS \\
\hline \multicolumn{10}{|c|}{ Propionic acid } \\
\hline Ileum & 42 & 46 & $28^{\mathrm{a}}$ & $59^{\mathrm{b}}$ & $45^{\mathrm{c}}$ & 2 & + & $* *$ & * \\
\hline Caecum & 229 & 252 & $211^{\mathrm{a}}$ & $292^{\mathrm{b}}$ & $217^{\mathrm{a}}$ & 11 & $* *$ & $* * *$ & NS \\
\hline Colon & 145 & 160 & $144^{\mathrm{a}}$ & $188^{\mathrm{b}}$ & $126^{\mathrm{c}}$ & 7 & $* *$ & $* * *$ & NS \\
\hline \multicolumn{10}{|l|}{ Butyric acid } \\
\hline Ileum & 22 & 21 & $15^{\mathrm{a}}$ & $27^{\mathrm{b}}$ & $23^{\mathrm{b}}$ & 2 & NS & $* *$ & NS \\
\hline Caecum & 51 & 50 & $56^{\mathrm{ab}}$ & $66^{\mathrm{a}}$ & $45^{\mathrm{b}}$ & 5 & $*$ & $* *$ & NS \\
\hline Colon & 35 & 41 & $38^{\mathrm{ab}}$ & $45^{\mathrm{a}}$ & $33^{\mathrm{b}}$ & 3 & $*$ & $* *$ & NS \\
\hline \multicolumn{10}{|c|}{ Organic acids } \\
\hline Ileum & 427 & 462 & $369^{\mathrm{a}}$ & $513^{\mathrm{b}}$ & $451^{\mathrm{c}}$ & 11 & $* *$ & $* * *$ & NS \\
\hline Caecum & 728 & 833 & $731^{\mathrm{a}}$ & $889^{\mathrm{b}}$ & $721^{\mathrm{a}}$ & 35 & $* *$ & $* * *$ & NS \\
\hline Colon & 611 & 660 & $577^{\mathrm{a}}$ & $722^{\mathrm{b}}$ & $608^{\mathrm{a}}$ & 21 & $* *$ & $* *$ & NS \\
\hline \multicolumn{10}{|l|}{ SCFA } \\
\hline Ileum & 193 & 207 & $143^{\mathrm{a}}$ & $265^{\mathrm{b}}$ & $192^{c}$ & 9 & + & $* * *$ & NS \\
\hline Caecum & 711 & 782 & $686^{\mathrm{a}}$ & $836^{\mathrm{b}}$ & $717^{\mathrm{a}}$ & 17 & $* * *$ & $* * *$ & NS \\
\hline Colon & 472 & 510 & $468^{\mathrm{a}}$ & $551^{\mathrm{b}}$ & $453^{\mathrm{a}}$ & 14 & $*$ & $* * *$ & NS \\
\hline
\end{tabular}

$* \mathrm{p}<0.05 ; * * \mathrm{p}<0.01 ; * * * \mathrm{p}<0.001 ;{ }^{+} \mathrm{p}<0.1 ; \mathrm{NS}=$ Non-significant.

${ }^{a}$ LF $=$ Low fibre diet; HF-CR = High fibre diet containing cassava residue; HF-BG = High fibre diet containing brewer's grain . 
highest value for pigs fed diet HF-CR $(p<0.05)$. The concentration of propionic acid in the ileum and caecum was lowest for pigs fed diet LF, followed by diet HF-BG and HF-CR $(\mathrm{p}<0.01)$, whereas in the colon it was lowest for pigs fed diet HF-BG followed in increasing order by diet LF and diet HF-CR ( $\mathrm{p}<0.001)$. Pigs fed diet HF-CR had the highest concentration of butyrate in all intestinal segments, while it was lowest in ileum for pigs fed diet HF and in the caecum and colon for pigs fed diet HF-BG $(\mathrm{p}<0.01)$. The highest concentration of $\mathrm{OA}$ in the ileum was observed for diet HF-CR, followed in descending order by diet HF-BG and diet LF $(\mathrm{p}<0.001)$. In the caecum and colon, the concentration of OA was similar in diets LF and HF-BG, whereas it was greater in diet in diet HF-CR $(\mathrm{p}<0.01)$.

In the ileum, there was a diet by breed interaction for the concentration of propionic acid $(\mathrm{p}<0.05)$, such that the difference in propionic acid concentration between diets HF-CR and HF-BG was higher in MC pigs than in LY pigs.

The molar proportions (of total OA) of lactic acid and SCFA, and of individual OA (acetic, propionic and butyric acid) (of total SCFA) in each segment did not differ between MC and LY pigs ( $p>0.05)$. With the exception of the molar proportions (of total OA) of lactate (0.61, 0.48 and 0.57 in diets LF, HF-CR and HF-BG, respectively; $\mathrm{p}<0.01$, SEM 0.05) and SCFA $(0.39,0.52$ and 0.43 in diets LF, HF-CR and HF-BG, respectively; $\mathrm{p}<0.01$, SEM 0.04) in ileum, diet had no effect on the molar proportions in all gut segments. The molar proportions of acetate, propionate, butyrate in the ileum, caecum and colon were $0.67,0.22$, $0.11 ; 0.61,0.32,0.07$ and $0.61,0.31,0.08$, respectively.

\section{DISCUSSION}

\section{Gut morphology}

Diet had an impact on the small intestinal morphology in the present study, in particular in the jejunum and ileum, while no effects were seen in the duodenum. The villus height in the jejunum and ileum was greater in diet HF-BG than in diets HF-CR and LF. This could be due to the lower soluble NSP content in diet HF-BG than in diets HF-CR and LF. Earlier studies have shown reduced villus height and increased crypt depth when weaned pigs were fed diets with high soluble NSP content (McDonald et al., 2001; Hedemann et al., 2006). Pigs fed the high fibre diets (diets HF-CR and HF-BG) had greater villus width and lower crypt density in ileum compared to pigs fed diet LF. A greater villus width in pigs fed high fibre diets has also been reported by others (Jin et al., 1994; Martin, 2010). Moreover, more substrate was available for microbial fermentation in the high-fibre diets and as a result the concentration of SCFA in the ileum was higher than on diet LF. The SCFA stimulate cell proliferation and cell growth in the gut. Thus, changes in the small intestinal epithelial morphology induced by DF can be due to the trophic effect of SCFA (Montagne et al., 2003).

Interestingly, there was a breed effect on the small intestinal morphology in the ileum, while there were no breed related differences in the duodenum and jejunum. Mong Cai pigs had shorter villi, smaller villus width and greater crypt density in the ileum than LY pigs. It has been suggested that differences in gut morphology can be explained by differences in digesta transit time and gut microbial activity (Freire et al., 2003). A major part of the digested nutrients are absorbed in the proximal small intestine. This together with a rapid digesta passage and low microbial activity, results in less exposure to digesta components compared with the situation in the more distal small intestine. The MC pigs in the present study had a longer total tract mean retention time of solids than the LY pigs (Ngoc et al., 2012) allowing for longer contact between digestion products and absorptive surfaces (Guixin et al., 1995). Moreover, LAB counts were higher and E. coli counts were lower in MC than in LY pigs.

\section{Bacterial counts and gut environment}

Diet had an impact on bacterial counts, with highest LAB counts in stomach and ileum on the high fibre diets. This is in line with previous studies (Bach Knudsen et al., 1991; Bach Knudsen et al., 1993; Jensen, 2001; Simon, 2001) showing that diets varying in fibre content and fibre properties may lead to changes in the gut environment due to interactions between the diet and the gut microflora. In the present study, the lowest E. coli counts were found for the high-fibre diet with high content of soluble NSP (HF$\mathrm{CR})$. Highest LAB counts in stomach were found in the diet with high content of soluble NSP (HF-CR). In contrast, Wang et al. (2003) showed that soluble dietary fibre tended to decrease the gastric LAB counts, whereas insoluble dietary fibre tended to increase the gastric LAB counts.

The diet HF-CR resulted in lower $\mathrm{pH}$ in the ileum, caecum and colon, and higher content of OA at these sites compared to diets LF and HF-BG. This can be explained that the soluble polysaccharides are more readily available for the microbial fermentation (Bach Knudsen and Jørgensen, 2001; Wang et al., 2003) with subsequent production of OA and thereby changes in $\mathrm{pH}$ (Jensen, 2001; Högberg and Lindberg, 2004a). However, the current study could not confirm a relationship between the concentration of $\mathrm{OA}$ and $\mathrm{pH}$ in the ileum, caecum and colon as shown by Högberg and Lindberg (2004b, 2006). Furthermore, in accordance with earlier findings (Jensen, 2001; Högberg and Lindberg 2004a; Giang et al., 2010) we found that lactic acid was the principal OA in the small intestine, while SCFA dominated in the large intestine. 
Increased dietary NSP content increased the concentration of lactate, acetate, propionate, butyrate and SCFA in the ileum, with the highest value for diet HF-CR. This could be related to higher $\mathrm{LAB}$ counts and to production of either lactic acid alone or both lactic and acetic acid depending on the LAB population (Cummings and Macfarlane, 1991). Consequently, the concentrations of acetic, propionic and butyric acid may be indirectly affected by the LAB numbers and their major fermentation products (Giang et al., 2010).

In the present study, there were interactions between breed and diet on LAB count and concentration of propionic acid in the ileum, with increased fibre level in the diet in combination with a high soluble fibre content having a greater impact on the $\mathrm{LAB}$ count and the concentration of propionic acid in the ileum of MC pigs than of LY pigs. This suggests differences in the gut microbiota activity and/or composition between MC and LY pigs.

\section{CONCLUSIONS}

The present study shows that fibre level and fibre source had an impact on small intestinal morphology, in particular in the ileum. This effect was parallel with fibre related effects on LAB and E. coli counts in the GIT, and on the gut environment. Moreover, there were differences between pig breeds in small intestinal morphology, counts of LAB and $E$. coli along the GIT and in gut environment.

\section{ACKNOWLEDGEMENTS}

This study was financed by Sida-SAREC (Swedish International Development Cooperation Agency Department for Research Cooperation), through the regional MEKARN program and the Swedish University of Agricultural Sciences. The authors would like to thank the researchers at the Department of Animal Nutrition and Forage and staff of the Centre of Animal Feed Testing and Conservation of the National Institute of Animal Sciences for their help in carrying out the study.

\section{REFERENCES}

Amino Quant 1990. Amino Quant (Operator's Handbook). HP No 01090 90025. Hewlett Packard Company. Printed in the Federal Republic of Germany.

AOAC. 1990. Official methods of analysis. 15th edition. Association of Official Analytical Chemists, Arlington, Virgina, USA.

Bach Knudsen, K. E. 1997. Carbohydrate and lignin contents of plant materials used in animal feeding. Anim. Feed Sci. Technol. 67:319-338.

Bach Knudsen, K. E. and H. Jørgensen. 2001. Intestinal degradation of dietary carbohydrates-from birth to maturity. In: Digestive Physiology in Pigs (Ed. J. E. Lindberg and B. Ogle). CABI Publishing, Wallingford. pp. 109-120.

Bach Knudsen, K. E., B. B. Jensen, J. O. Andersen and I. Hansen. 1991. Gastrointestinal implications in pigs of wheat and oat fractions. 2. Microbial activity in the gastrointestinal tract. Br. J. Nutr. 65:233-248.

Bach Knudsen, K. E., B. B. Jensen and I. Hansen. 1993. Oat bran but not a h-glucan-enriched oat fraction enhances butyrate production in the large intestine of pigs. J. Nutr. 123:12351247.

Cummings, J. H. and G. T. Macfarlane. 1991. The control and consequences of bacterial fermentation in the human colon. J. Appl. Microbiol. 70:443-459.

Freire, J. P. B., A. J. G. Guerreiroa, L. F. Cunhaa and A. Aumaitre. 2000. Effect of dietary fibre source on total tract digestibility, caecum volatile fatty acids and digestive transit time in the weaned piglet. Anim. Feed Sci. Technol. 87:71-83.

Freire, J. P. B., R. I. M. Dias, L. F. Cunha and A. Aumaitre. 2003. The effect of genotype and dietary fibre level on the caecal bacterial enzyme activity of young piglets: digestive consequences. Anim. Feed Sci. Technol. 106:119-130.

Food components Adhoc Committee. 2002. Natural Resources Study Committee, Science and Technology Agency. Manual of Analytical Methods, Japan. pp. 185-189.

Giang H. H, T. Q. Viet, B. Ogle and J. E. Lindberg. 2010. Growth performance, digestibility, gut environment and health status in weaned piglets fed a diet supplemented with potentially probiotic complexes of lactic acid bacteria. Livest. Sci. 129:95-103.

Guixin, Q., M. W. A. Verstegen and M. W. Bosch. 1995. Variarion of digestive between genetically different pig populations: a review. J. Anim. Physiol. Anim. Nutr. 73:233-242.

Hedemann, M. S., M. Eskildsen, H. N. Lærke, C. Pedersen, J. E. Lindberg, P. Laurinen and K. E. Bach Knudsen. 2006. Intestinal morphology and enzymatic activity in newly weaned pigs fed contrasting fibre concentrations and fibre properties. J. Anim. Sci. 84:1375-1386.

Hentges, D. J. 1992. Gut flora and disease resistance. In: Probiotics: The Scientific Basis (Ed. R. Fuller). Chapman and Hall, London. pp. 87-110.

Högberg, A. and J. E. Lindberg. 2004a. Influence of cereal nonstarch polysaccharides and enzyme supplementation on digestion site and gut environment in weaned piglets. Anim. Feed Sci. Technol. 116:113-128.

Högberg, A. and J. E. Lindberg. 2004b. Influence of cereal nonstarch polysaccharides on digestion site and gut environment in growing pigs. Livest. Prod. Sci. 87:121-130.

Högberg, A. and J. E. Lindberg. 2006. The effect of level and type of cereal non-starch polysaccharides on the performance, nutrient utilization and gut environment of pigs around weaning. Anim. Feed Sci. Technol. 127:200-219.

Jensen, B. B. 2001. Possible ways of modifying type and amount of products from microbial fermentation in the gut. In: Gut Environment of Pigs (Ed. A. Piva, K. E. Bach Knudsen and J. E. Lindberg). Nottingham University Press, Nottingham. pp. 181-200.

Jin, L., L. P. Reynold, D. A. Redmer, J. S. Caton and J. D. 
Crenshaw. 1994. Effects of dietary fibre on intestinal growth, cell proliferation, and morphology in growing pigs. J. Anim. Sci. 72:2270-2278.

Larsson, K. and S. Bengtsson. 1983. Bestämning av lätt tillgängliga kolhydrater $\mathrm{i}$ växtmaterial (Determination of nonstructural carbohydrates in plant material). Method description no 22 Uppsala, Sweden: National Laboratory of Agricultural Chemistry.

Martins, C., M. Pinho, M. M. Lordelo, L. F. Cunha, J. Carvalho and J. P. B. Freire. 2010. Effect of brewer's grain on intestinal microbial activity and mucosa morphology of weaned piglets. Livest. Sci. 133:132-134.

May, T., R. I. Mackie, G. C. Fahey, J. C. Cremin and K. A. Garleb. 1994. Effect of fibre source on short-chain fatty acid production and on the growth and toxin production by Clostridium difficile. Scand. J. Gastroenterol. 29:916-922.

McDonald, D. E., D. W. Pethick, B. P. Mullan and D. J. Hampson. 2001. Increasing viscosity of the intestinal contents alters small intestinal structure and intestinal growth, and stimulates proliferation of enterotoxigenic Escherichia coli in newlyweaned pigs. Br. J. Nutr. 86:487-498.

Minitab. 2000. Statistical software version 13.31. User's Guide to Statistics. Minitab, PA, USA.

Montagne, L., J. R. Pluske and D. J. Hampson. 2003. A review of interactions between dietary fibre and the intestinal mucosa, and their consequences on digestive health in young nonruminant animals. Anim. Feed Sci. Technol. 108:95-117.

NRC. 1998. Nutrient requirements of swine ( $10^{\text {th }}$ edition). National Academy Press, Washington, DC, USA.
Ngoc, T. T. B., N. T. Len and J. E. Lindberg. 2012. Impact of fibre intake and fibre source on digestibility, gastro-intestinal tract development, mean retention time and growth performance of indigenous (Mong Cai) and exotic (LandracexYorkshire) pigs. Animal (revision).

NIAH. 2001. Composition and Nutritive Value of Animal Feed in Vietnam. National Institute of Animal Husbandry, Agricultural Publishing House, Hanoi, Vietnam.

Simon, O. 2001. The influence of feed composition on protein metabolism in the gut. In: Gut environment of pigs (Ed. A. Piva, K. E. Bach Knudsen and J. E. Lindberg). Nottingham University Press, Nottingham. pp. 63-84.

Theander, O., P. Åman, E. Westerlund, R. Andersson and D. Pettersson. 1995. Total dietary fibre determined as neutral sugar residues, uronic acid residues, and Klason lignin (The Uppsala Method): Collaborative study. J. AOAC Int. 78:10301044.

Van Soest, P. J., J. B. Robertson and B. A. Lewis. 1991. Methods for dietary fibre, neutral detergent fibre and non-starch polysaccharides in relation to animal nutrition. J. Dairy Sci. 74:3583-3597.

Wang, X. and G. R. Gibson. 1993. Effects of the in vitro fermentation of oligofructose and inulin by bacteria growing in the human large intestine. J. Appl. Microbiol. 75:373-380.

Wang, J. F., D. F. Li, B. B. Jensen, K. Jakobsen, J. J. Xing, L. M. Gong and Y. H. Zhu. 2003. Effect of type and level of fibre on gastric microbial activity and short-chain fatty acid concentrations in gestating sows. Anim. Feed Sci. Technol. 104:95-110. 